\title{
Cleft deformities in adults and children aged over six years in Nigeria: Reasons for late presentation and management challenges
}

This article was published in the following Dove Press journal:

Clinical, Cosmetic and Investigational Dentistry

27 November 2009

Number of times this article has been viewed

\author{
Wasiu L Adeyemo' \\ Mobolanle O Ogunlewe' \\ Ibironke Desalu² \\ Akinola L Ladeinde' \\ Bolaji O Mofikoya ${ }^{3}$ \\ Michael O Adeyemi ${ }^{4}$ \\ Adegbenga A Adepoju ${ }^{4}$ \\ Olufemi O Hassan ${ }^{4}$ \\ 'Department of Oral and Maxillofacial \\ Surgery, Faculty of Dental Sciences, \\ ${ }^{2}$ Department of Anaesthesia, \\ ${ }^{3}$ Department of Surgery, Faculty of \\ Clinical Sciences, College of Medicine, \\ University of Lagos, Lagos, Nigeria; \\ ${ }^{4}$ Department of Oral and Maxillofacial \\ Surgery, Lagos University Teaching \\ Hospital, Lagos, Nigeria
}

\begin{abstract}
In developing countries, untreated cleft lips and palates are found with increasing frequency and patients often present to the surgeon far past the optimal time for closure of the cleft deformities. A prospective study was conducted between March 2007 and September 2009, to identify the reasons and treatment challenges of delayed presentation of cleft lip and palate deformities at the Lagos University Teaching Hospital, Nigeria. Out of a total of 150 patients with cleft defects during the period, 43 (28.7\%) were adults and children aged over six years. The mean age of these patients at the time of presentation was 17.3 years. The most common reasons for late presentation were lack of money (56.7\%), lack of health care services nearby (18.4\%), and lack of awareness of treatment availability (13.3\%). Common challenges in these patients included surgical, orthodontic, speech, anesthetic, and psychological. Although adult clefts were significantly enlarged in three dimensions the anatomic landmarks were easier to discern than in an infant. However, extensive soft tissue dissection in adult cleft lip repair resulted in significant postoperative edema. Closure of wide palatal cleft often required the use of adjunct intraoral flaps. Despite late presentation, surgical outcome of these patients was satisfactory and comparable to cleft repair in infants.
\end{abstract}

Keywords: cleft deformities, adults, adolescents, late presentation, management, challenges

\section{Introduction}

Orofacial clefts are common congenital malformations whose etiology is complex and likely to have both genetic and environmental etiology. ${ }^{1}$ Although numerous techniques and protocols are employed in the repair of this congenital deformity, the surgical literature is consistent in recommending early repair, typically completing primary repair of the lip and palate by the age of two years. ${ }^{2}$ A commonly accepted protocol in many surgical textbooks is repair of a cleft lip at 10 to 12 weeks of age, followed by primary palatoplasty at nine to 12 months of age, before development of speech. ${ }^{1-4}$ It is well known that timely closure of palatal defect is associated with improved speech outcome, ${ }^{3}$ and late closure of the palate has been clearly demonstrated to give a poor outcome. ${ }^{4}$ In addition, delayed repair of the cleft can lead to impaired family and societal relationships with potential long-term psychological effects on the child. ${ }^{5}$ Unfortunately in developing countries untreated cleft lips and palates are found with increasing frequency and patients often present to the surgeon far past the optimal time for closure of the cleft deformities. ${ }^{2,3}$ The potential reasons for this are many, including distance to health care, limited access to specialized health care, unavailability of health care services, lack of awareness of treatment availability, cultural beliefs, superstition, and lack of money or time. ${ }^{2,3,6,7}$
Correspondence: Wasiu L Adeyemo Department of Oral and Maxillofacial Surgery, Faculty of Dental Sciences, College of Medicine, University of Lagos, PMB I2003, Lagos, Nigeria Email lanreadeyemo@yahoo.com 
Despite the fact that late presentation for surgical correction is common in patients with cleft deformities in Nigeria and other developing countries, the reasons for this have not been reported in Nigeria to date. It is important to know the common reasons for late presentation so that government health departments and international aid organizations can formulate policies to reduce the frequency of this problem.

The aims of the study were to identify the reasons for late presentation, and the treatment challenges of cleft deformities in adults and children aged over six years in Lagos, Nigeria.

\section{Methods}

This was a prospective study conducted at the Department of Oral and Maxillofacial Surgery, Lagos University Teaching Hospital, Lagos, Nigeria between March 2007 and September 2009, to identify the reasons for late presentation and treatment challenges of cleft deformities in adults and children aged over six years in Lagos, Nigeria.

A questionnaire administered by one of the authors (WLA) was used to collect information on the reasons for late presentation. Either the patient or the parent/caregiver of each patient was interviewed to elucidate the reason(s) for such a late presentation. A proforma containing the following information was also recorded for each patient: age and gender of patients, type of cleft defect, type of surgical intervention, repair technique, as well as any postoperative complications.

Of those patients who had undergone repair of cleft deformities during the study period, only those who were aged six years and above were included in the study.

\section{Anesthetic techniques}

Generally, surgical repair was carried out under general anesthesia. However, some cases of cleft lip surgery in patients aged over 12 years were done under local anesthesia using $2 \%$ xylocaine with adrenaline $(1: 80,000)$.

\section{General anesthetic technique}

Prior to induction, electrocardiograph (ECG) leads, blood pressure cuff, pulse oximeter probe, and precordial stethoscope were applied and pre-induction values obtained. Induction was either inhalational (with incremental halothane) or intravenous (using thiopentone or propofol). When the depth of anesthesia was judged to be adequate, the trachea was intubated with an appropriate sized south-polar (for cleft lip repair only) or reinforced (for palatal surgery) endotracheal tube under deep inhalational anesthesia or muscle relaxants, using external laryngeal pressure if needed. Correct placement of the tracheal tube was confirmed by auscultation and capnography, the tube was securely fixed and the patient positioned for surgery.

The surgical site was infiltrated with adrenaline (1:200,000) before making an incision. Maintenance of anesthesia was with isoflurane and all patients were ventilated after administration of a muscle relaxant. Analgesia was provided with fentanyl, paracetamol, diclofenac, or pethidine. Additional monitoring included capnography and temperature. At the end of surgery, patients were extubated when fully awake with protective airway reflexes.

\section{Surgical techniques}

Unilateral cleft lip repair was done using Millard's rotation advancement technique or Tennison-Randall triangular technique. Primary or secondary lip surgery for bilateral cleft lip defects were achieved using a fork flap technique. Cleft of the hard and soft palate was repaired using von Langenbeck's double palatal flap technique. Other intraoral flaps were combined with von Langenbeck's flap when necessary.

\section{Data analysis}

Data were analyzed using SPSS software (version 12.0 for Windows; SPSS Inc., Chicago, IL, USA). Data are presented in descriptive statistics.

\section{Results}

A total of 150 patients had undergone repair of cleft deformities during the study period. Of these, 43 (28.7\%) were aged over six years and were included in the analysis. The mean age \pm standard deviation (SD) of these patients was $17.3 \pm 8.9$ years (range, 6-37 years). Most patients $(62.8 \%)$ were found in the age group 6-20 years; and with an almost equal male-to-female ratio (Table 1). The most common congenital cleft deformity was unilateral cleft lip \pm alveolus $(39.5 \%)$ followed by cleft of the hard and soft palate (Figures 1, 2, and 3, Table 1). Thirty (70\%) of these patients presented with primary (unrepaired) defects, while 13 patients (30\%) presented with secondary (previously repaired) defects.

Reasons for the delay in presentation for surgical repair are summarized in Table 2. The most common reasons were lack of money $(56.7 \%)$, followed by lack of health care services nearby (18.4\%) and lack of awareness of treatment availability (13.3\%). Reason for delayed presentation in two patients was fear of death from surgery.

\section{Surgical repair and techniques}

Cleft deformities in adults and older children were characterized with significant enlargement in three dimensions. 
Table I Characteristics of patients with delayed presentation of cleft deformities

\begin{tabular}{lll}
\hline Age range (years) & Number & (\%) \\
\hline $6-10$ & 14 & $(32.6)$ \\
II-20 & 13 & $(30.2)$ \\
$2 I-30$ & 10 & $(23.2)$ \\
$31-37$ & 6 & $(14.0)$ \\
Total & 43 & $(100)$ \\
Gender & & \\
Male & 21 & $(48.8)$ \\
Female & 22 & $(51.2)$ \\
Total & 43 & $(100)$ \\
Types of cleft deformity & & \\
Unilateral cleft lip \pm alveolus & 17 & $(39.5)$ \\
Bilateral cleft lip \pm alveolus & 2 & $(4.6)$ \\
Unilateral cleft lip and palate & 6 & $(14.0)$ \\
Bilateral cleft lip and palate & 2 & $(4.6)$ \\
Cleft hard and soft palate & 9 & $(21.0)$ \\
Isolated cleft of soft palate & 7 & $(16.3)$ \\
Total & 43 & $(100)$ \\
\hline
\end{tabular}

The repair of the cleft palate often required significant soft tissue dissection and the use of adjunct intraoral flaps. For primary surgical repair, an equal number of cleft lip and palate corrections were undertaken (Table 3). Palatal fistula repair was the most common secondary cleft repair (Table 3). Unilateral cleft lip repair was achieved using Millard's rotation advancement technique or Tennison-Randall triangular technique (Figure 4). Primary or secondary lip surgery for bilateral cleft lip defects was achieved using fork flap technique (Figure 5). Clefts of the hard and soft

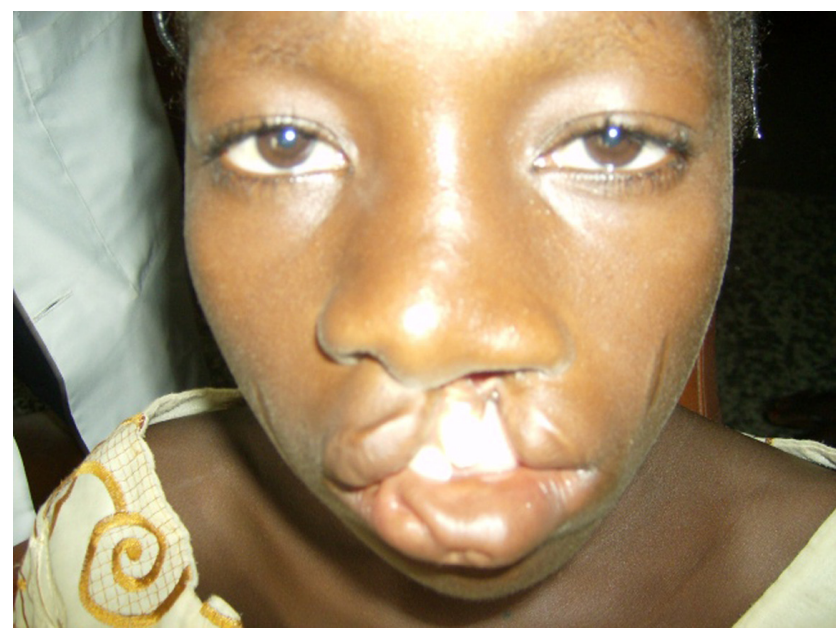

Figure I A I4-year-old girl with a complete unilateral cleft of the lip and alveolus.

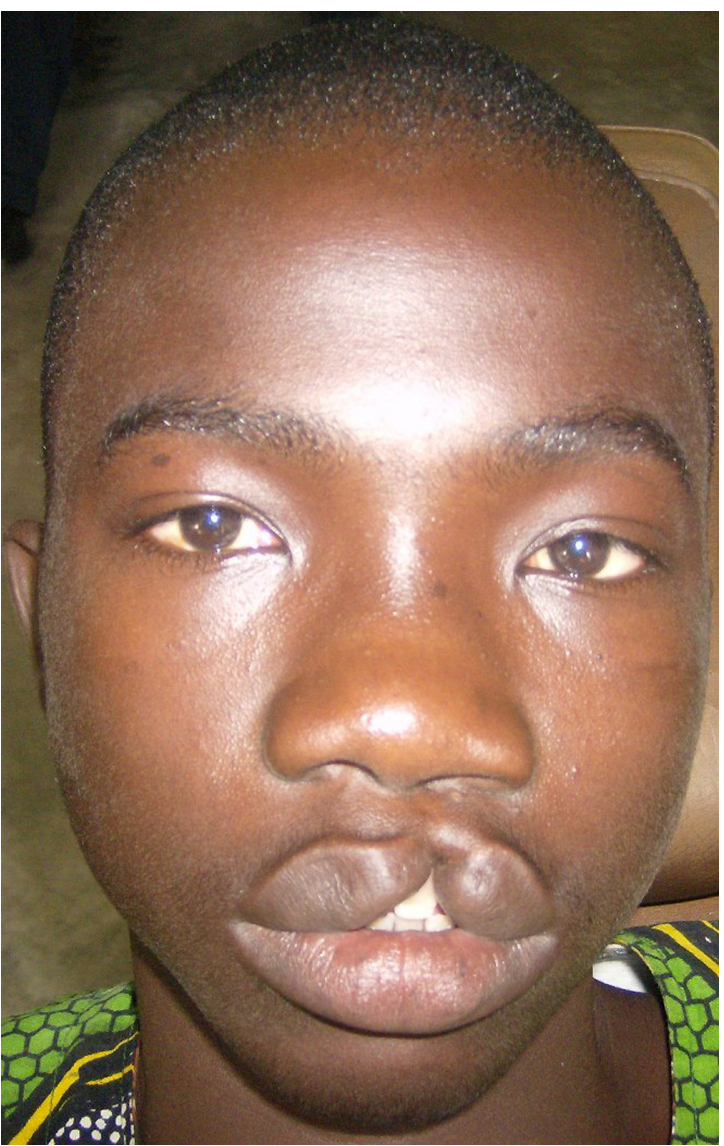

Figure 2 A 12-year-old boy with an incomplete cleft of the lip.

palate were repaired using von Langenbeck's double palatal flap technique (Figure 6). Tongue flap $(\mathrm{n}=2)$ and buccal fat pad pedicled flap $(n=2)$ were used as an adjunct flap in palatal repair in four patients. These adjunct flaps were used in conjunction with a palatal flap in cases of wide palatal

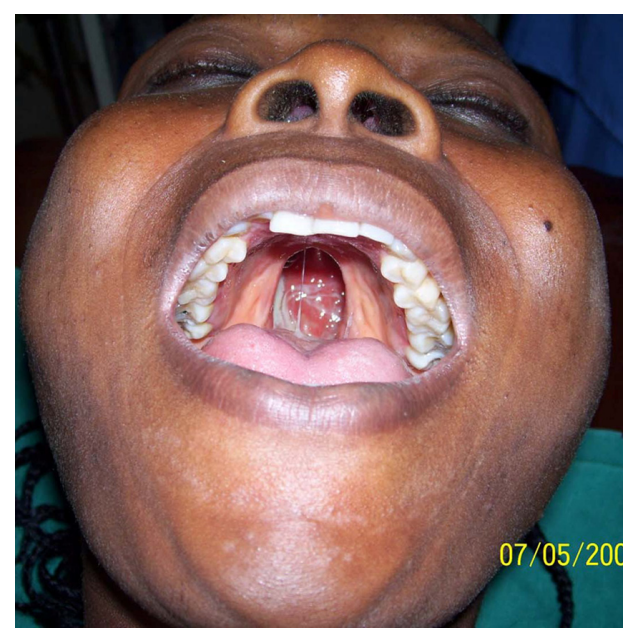

Figure 3 A 35-year-old woman with a cleft of hard and soft palate. 
Table 2 Reasons for late presentation

\begin{tabular}{lll}
\hline Reason & Number & (\%) \\
\hline Lack of money & 34 & $(56.7)$ \\
Lack of awareness of treatment availability & 8 & $(13.3)$ \\
Fear of death from surgery & 2 & $(3.3)$ \\
Superstition & 5 & $(8.3)$ \\
Distance to health services & $\mathrm{II}$ & $(18.4)$ \\
Total & 60 & $(100)^{\prime}$ \\
\hline
\end{tabular}

Note: 'More than one reason was given by some patients.

cleft, and additionally in difficult fistula repair resulting from scarification or inadvertent tearing of nasal mucosa during flap mobilization.

Healing was uneventful in most patients, however, considerable postoperative edema was observed following lip repair in adults. Wound dehiscence leading to palatal fistula was seen in three patients $(7.1 \%)$.

\section{Discussion}

It is widely agreed that early assessment and commencement of counseling and treatment of patients with congenital cleft lip and palate defects improve the overall outcome of the patient from cosmetic, speech and psychological perspectives. ${ }^{3,5}$ Some authors have reported subsequent depression, social avoidance, and feeling of guilt, which often persisted into the adolescent years of the child and adversely affected the child's emotional development. ${ }^{5}$ Lack of nutritional counseling has also been reported to increase the risk of malnutrition in children with a cleft palate; with a subsequent predisposition to developmental problems. ${ }^{3}$ Quality of life in family having small children with cleft defects have also been reported to be severely reduced. ${ }^{8}$ Due to these facts, early surgical and supportive interventions have been widely recommended. Unfortunately, late presentation of patients with cleft deformities in developing countries is still very common. ${ }^{2,3,6,7}$

For the purpose of this study, only patients who were aged six years or older were included. It is acknowledged

Table 3 Type of surgical procedure

\begin{tabular}{lll}
\hline Type of repair & Number & (\%) \\
\hline Unilateral cleft lip repair & 15 & $(34.9)$ \\
Cleft palate repair & 15 & $(34.9)$ \\
Lip revision & 6 & $(13.9)$ \\
Fistula repair & 7 & $(16.3)$ \\
Total & 43 & $(100)$ \\
\hline
\end{tabular}

A)

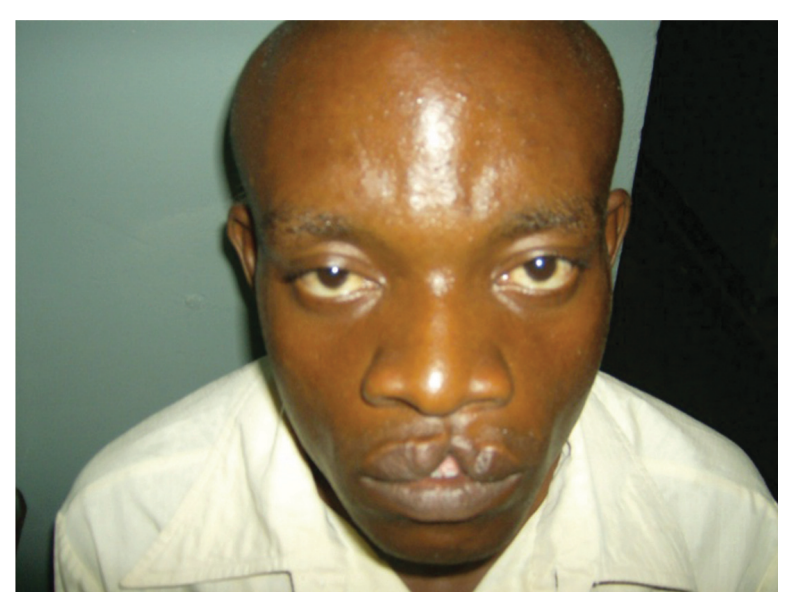

B)

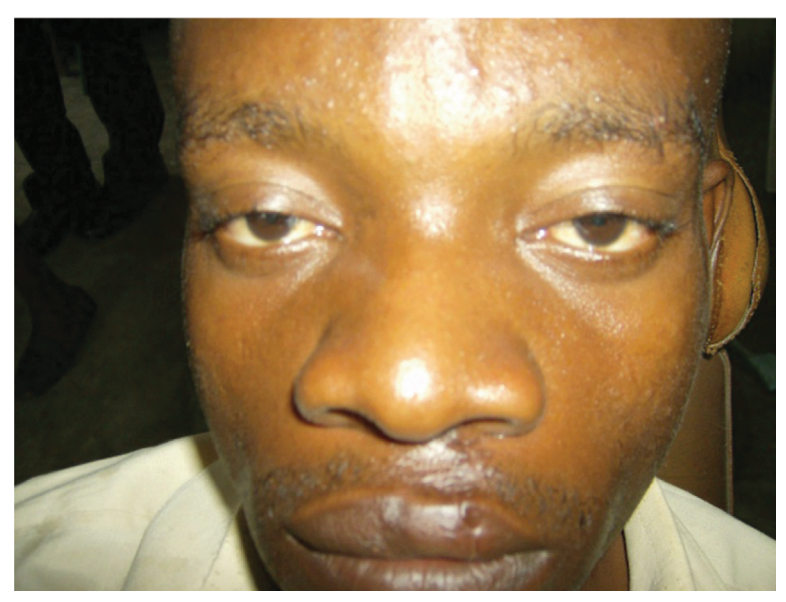

Figure 4 Repair of an incomplete cleft of the lip using Tennison-Randall triangular technique under local anesthesia: A) preoperative appearance; B) postoperative appearance.

that patients younger than six years who presented later than the recommended age of surgical repair (3-18 months) were also commonly seen in the studied environment. In Nigeria, children are expected to commence primary school at the age of six years, therefore many children with cleft lip and/or palate deformities who have been kept indoors due to the "shame" associated with the defect are often exposed to the outside world for the first time at this age.

About three out of every 10 cleft deformities treated in our centre during the study period were seen in patients aged over six years. The majority of these patients $(62.8 \%)$ were in the age group of 6-20 years. The most common reasons for the delayed presentation and repair were lack of money. This is not unexpected because Nigeria is a developing country where the majority of its citizens live on less than one US dollar a day; and on average, US $\$ 400$ is required for cleft lip surgery. However, all the patients treated in our clinic, within the study period, were treated free 
A)

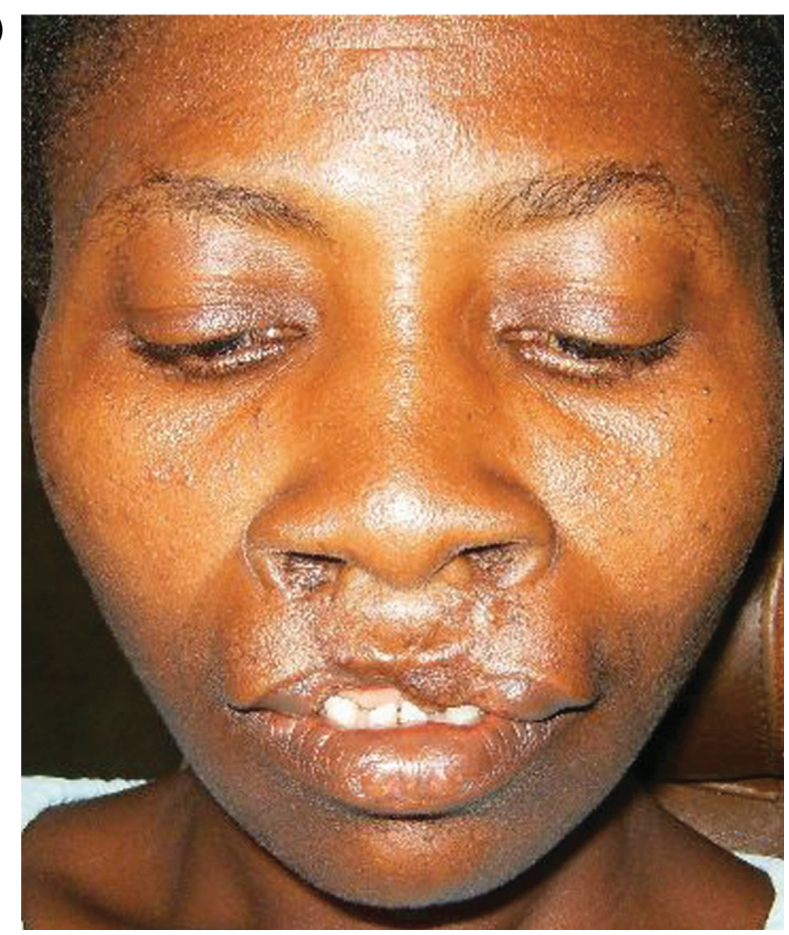

B)

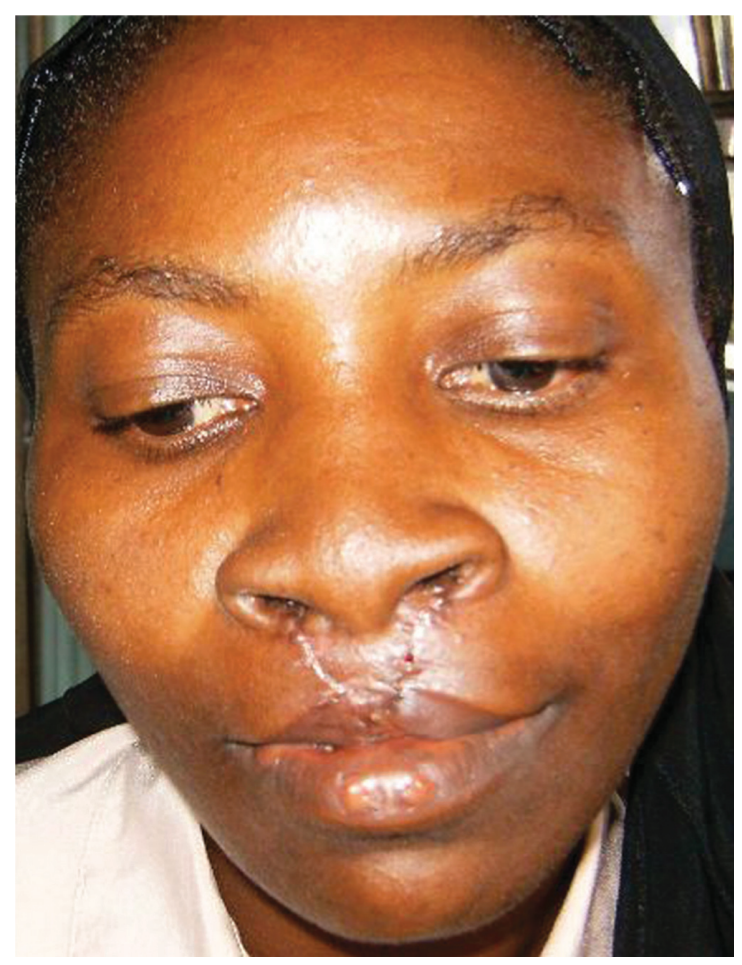

Figure 5 Surgical revision of bilateral cleft lip repair using fork flap technique: A) preoperative appearance; B) postoperative appearance.

(courtesy of sponsorship by an American nongovernmental, nonprofit organization). The problem of lack of finances as a reason for late presentation of medical problems is certainly endemic throughout developing countries. ${ }^{3}$ The problem is compounded for rural people, as they must pay for travelling and accommodation expenses in addition to the medical services at the health care center where such surgery can be provided. ${ }^{3}$

Schwarz and $\mathrm{Khadka}^{3}$ reported that the main reasons for late presentations of cleft lip and palate in Nepal were: lack of knowledge of availability of services (31\%), lack of services near at hand (29\%), lack of finance (24\%) and lack of time (13\%).
A)

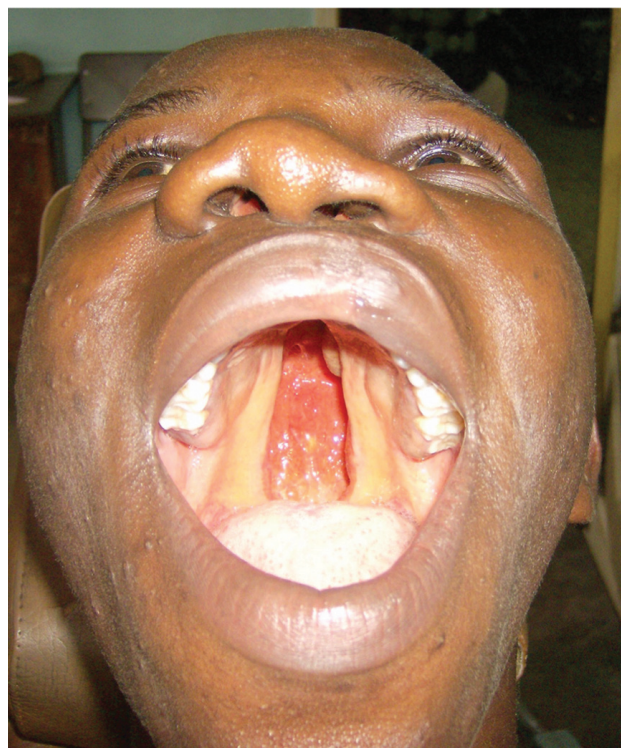

B)

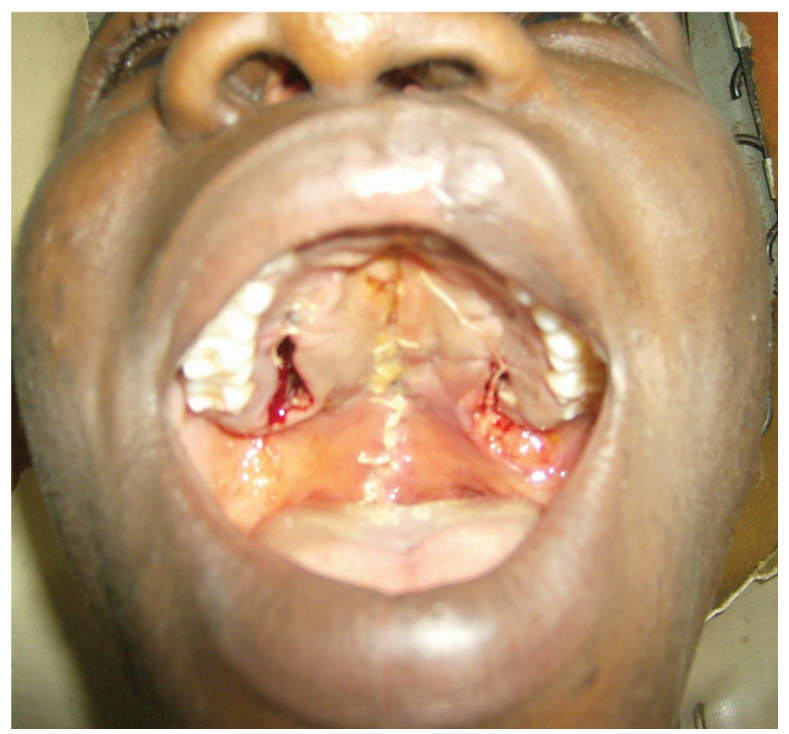

Figure 6 Repair of a complete cleft of the palate using von Langenbeck's technique: A) preoperative appearance; B) postoperative appearance. 
In the present study, distance to health services was the second most common reason for late presentation. Therefore, bringing surgical services to district hospitals would alleviate this problem. This approach would also lessen much of the financial burden and time constraints associated with travelling to a regional center by bringing the health care closer to home. ${ }^{3}$

The third most common reason cited for late presentation was a lack of knowledge of the availability of surgical correction services. This indicates that increased access to primary health care services combined with providing primary health care workers with information regarding the availability of cleft lip and palate corrective services would also reduce the rate of late presentation. ${ }^{3}$ Radio advertising and the organization of a community outreach program are also suitable means of informing communities of the availability of orofacial cleft correction services.

Several challenges are encountered in the management of patients with delayed presentation of cleft lip and palate especially in adulthood and adolescence. These include surgical, orthodontic, speech, anesthetic, and psychological challenges. Although sound knowledge of the fundamentals of cleft surgery will certainly allow any surgeon to repair an adult cleft lip or palate adequately, obtaining the most favorable surgical outcome may require creative modification to the design of the cleft secondary to various factors, including the increased size of the adult cleft. ${ }^{2}$ Surgeons should be prepared to repair adult patients with cleft that are significantly enlarged in three dimensions. Closure will require significant soft-tissue dissection, as well as the possible use of biomaterials to repair wide palatal clefts. ${ }^{2}$ In the present study, tongue pedicled flap was successfully used as an adjunct flap for the repair of a wide palatal cleft and a palatal fistula. The tongue, due to its high vascularity, is a reliable donor site for oral reconstruction. ${ }^{9}$ Buccal fat pad (BFP) was also successfully employed for fistula repair and in cases of inadvertent tearing of the nasal mucosa during flap mobilization. BFP is another reliable pedicled flap for oral reconstruction; ${ }^{10,11}$ and has been previously employed in cleft palate surgery. ${ }^{12}$

It is noteworthy to mention that the transverse and antero-posterior dimension of the maxilla of adults with unrepaired cleft palate in the present study was near to normal. However, this was at the expense of normal speech; and most of these patients presented with either hyper/hyponasality.

The most striking factor in repairing an adult cleft lip is that the anatomic landmarks are appreciably easier to discern than in an infant. ${ }^{2}$ In addition, there is increased soft-tissue bulk that can be readily utilized during such adult repair, that is not present for repairs in infants. However, the relative dimensions of the adult cleft gap can be appreciably larger ${ }^{2}$ and as such aggressive soft-tissue dissection may be required. Additionaly blood loss in adults during cleft surgery is far more than in infants. Postoperatively, secondary to aggressive muscle dissection, complete cleft lip repairs in the present study had significant edema, as previously observed. ${ }^{2}$

Another important consideration in adult cleft lip repair is the presence of maxillary anterior teeth which are often protruded and protracted and may interfere with closure of the lip (Figure 7). This may create tension and a tenting effect on the lip repair. ${ }^{2}$ Although it is preferable to save the teeth if possible. However, if a tooth compromises adequate repair of the lip or is diseased, it should be extracted. ${ }^{2}$

In our experience, anesthetic challenges in the repair of cleft deformities in adults and older children were different from that of infants. Unlike in infants, intubation for general anesthesia for adult cleft repair was usually not difficult. In addition, the incidence of difficult laryngoscopy was found to be less than with infants. Unfortunately in adult cleft surgery there is the additional risk of tooth dislodgement during laryngoscopy. Unlike infant surgery cleft lip repair was possible under local anesthesia in adolescent and adult patients.

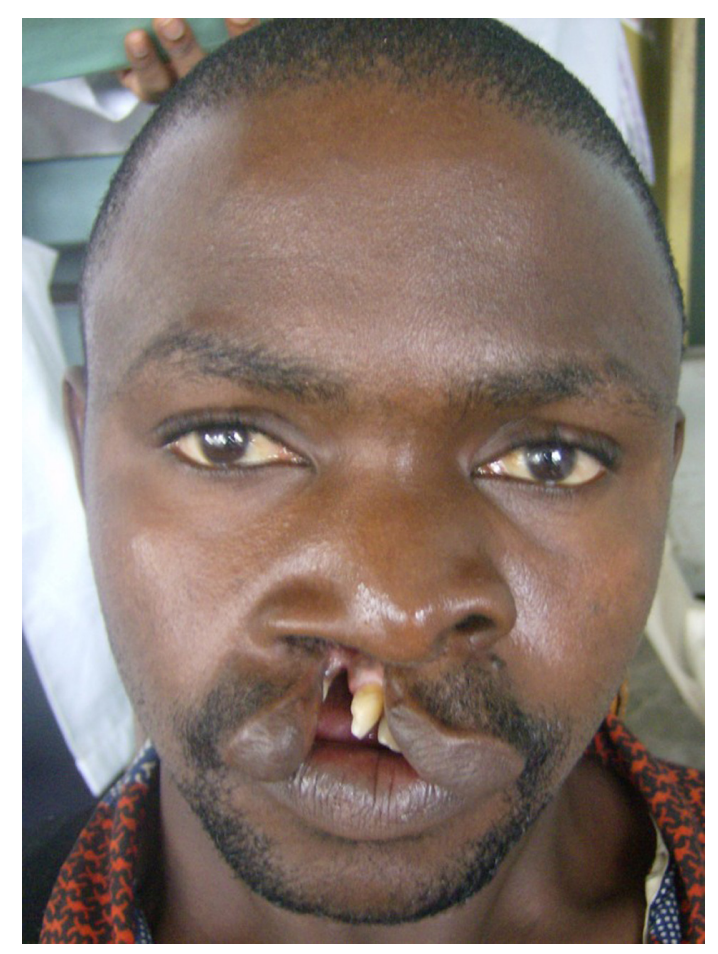

Figure $7 \mathrm{~A}$ rotated and protruding maxillary incisor in an adult with an unrepaired cleft lip and alveolus. 
In some cultures, many mothers of children with cleft deformities feel responsible for their child's ailment and often both mother and child are alienated by their family. ${ }^{2}$ Although, this rarely occurs in the Nigerian environment, most adult patients might require the services of a psychologist if they are to reintegrate into society and live a normal life after cleft repair. Delayed repair of the cleft deformities is reported to impair family and societal relationships with potential long-term psychological effects on the affected patient. $^{5}$

\section{Conclusions}

Delayed presentation of cleft lip and palate deformities in school age patients is not uncommon in the studied environment; constituting $28.7 \%$ of patients with cleft deformity seen during the period covered by the study. Due to the existing fee-for-service health care system in Nigeria, the major reason for late presentation of patients with cleft lip and palate in Nigeria was lack of finances. Challenges associated with cleft repair in adults and older children are quite different from that of infants. This must be well understood by cleft care providers in order to provide quality care for these patients. Despite late presentation by these patients for surgical repair, surgical outcomes were quite satisfactory.

\section{Acknowledgement}

Our sincere appreciation goes to Smile Train Organization (http://www.smiletrain.org/) for providing funds for the treatment of patients presented in the study. The authors report no conflict of interest in this work.

\section{References}

1. Rawashdeh MA, Abu-Hawas BJ. Congenital associated malformations in a sample of Jordanian patients with cleft lip and palate. J Oral Maxillofac Surg. 2008;66:2035-2041.

2. Aziz SR, Rhee ST, Redai. Cleft surgery in rural Bangladesh: reflections and experiences. J Oral Maxillofac Surg. 2009;67:1581-1588.

3. Schwarz R, Khadka SB. Reasons for late presentation of cleft deformity in Nepal. Cleft Palate Craniofac J. 2004;41:199-201.

4. Sell DA, Grunwell P. Speech results following late palatal surgery in previously unoperated Sri Lankan adolescents with cleft palates. Cleft Palate J. 1990;27:162-168.

5. Pelchat D, Bisson J, Richard N, Perreault M, Bouchard JM. Longitudinal effects of an early family intervention programme on the adaption of parents of children with a disability. Int J Nurs Stud. 1999;36: 465-477.

6. Nwoku AL. Experience on repair of unoperated cleft patients. Nig Med J. 1974;6:417-421.

7. Donkor P, Bankas DO, Agbenorku P, Plange-Rhule G, Ansah SK. Cleft lip and palate in Kumasi, Ghana: 2001-2005. J Craniofac Surg. 2007; 18:1376-1379.

8. Kramer FJ, Baethge C, Sinikovic B, Schliephake H. An analysis of quality of life in 130 families having small children with cleft lip/ palate using the impact of family scale. Int J Oral Maxillofac Surg. 2007;36:1146-1152.

9. Diaz FJ, Dean A, Alamillos FJ, Naval L. Tongue flap for reconstruction of the oral cavity. Head Neck. 1994;16:550-554.

10. Adeyemo WL, Ladeinde AL, Ogunlewe MO, Bamgbose BO. The use of buccal fat pad in oral reconstruction: A review. Niger Postgrad Med J. 2004;11:207-211.

11. Baumann A, Ewers R. Application of the buccal fat pad in oral reconstruction. J Oral Maxillofac Surg. 2000;58:389-392.

12. Jackson IT, Moreira-Gonzalez AA, Rogers A, Beal BJ. The buccal fat pad - a useful technique in cleft palate repair? Cleft Palate Craniofac J. 2004;41:144-151.
Clinical, Cosmetic and Investigational Dentistry

\section{Publish your work in this journal}

Clinical, Cosmetic and Investigational Dentistry is an international, peer-reviewed, open access, online journal focusing on the latest clinical and experimental research in dentistry with specific emphasis on cosmetic interventions. Innovative developments in dental materials, techniques and devices that improve outcomes

\section{Dovepress}

and patient satisfaction and preference will be highlighted. The manuscript management system is completely online and includes a very quick and fair peer-review system, which is all easy to use. Visit http://www.dovepress.com/testimonials.php to read real quotes from published authors. 